\title{
Anomalous Behavior of the Ethyl Group in the Aminolysis of $S$-Phenyl Acetate with Benzylamine in Acetonitrile
}

\author{
Ikchoon Lee," Hai Whang Lee, Byung Choon Lee, and Jin Heui Choi ${ }^{\dagger}$ \\ Deparment of Chemistry, Inha Lniversity, Inchon 402-751, Korea \\ ${ }^{\dagger}$ Department of Chemistry, Choongbuk National Universitw, Chongit 360-763, Korea \\ Received November 16, 2001
}

\begin{abstract}
The rates of the aminolysis of $S$-phenyl substituted-acetate series $\left(\mathrm{RC}(=\mathrm{O}) \mathrm{SC}_{6} \mathrm{H}_{7} \mathrm{Z}\right.$. with $\mathrm{R}=\mathrm{Me}$. Et. $i-\mathrm{Pr}, t-\mathrm{Bu}$ and $\mathrm{Bn})$ with benzylamines $\left(\mathrm{XC}_{6} \mathrm{H}_{4} \mathrm{CH}_{2} \mathrm{NH}_{3}\right)$ are not correlated simply with the Taft's polar $\left(\sigma^{\circ}\right)$ and/or steric effect constants $\left(E_{\mathrm{s}}\right)$ of the substituents due to abnormally enhanced rate of the substrate with $\mathrm{R}=\mathrm{Et}$. Furthermore. the cross-interaction constant. $\rho_{\mathrm{X}}$, is the largest with $\mathrm{R}=\mathrm{Et}$. These anomalous behaviors can only be explained by invoking the vicinal bond $(\sigma)$-antibond $\left(\sigma^{\prime}\right)$ charge transfer interaction between $\mathrm{C}-\mathrm{C}_{\alpha}$ and $\mathrm{C}-\mathrm{S}$ bonds. In the tetrahedral zwitterionic intermediate. $\mathrm{T}^{ \pm}$, formed with $\mathrm{R}=\mathrm{Et}$ the vicinal $\sigma_{\mathrm{cc}} \sigma_{\mathrm{C}}^{-} \mathrm{s}$ delocalization is the strongest with an optimum antiperiplanar arrangement and a narrow energy gap. $\Delta \varepsilon=\varepsilon_{\sigma^{*}}$ $-\varepsilon_{\sigma}$. Due to this charge transfer interaction, the stability of the intermediate increases (with the concomitant increase in the equilibrium constant $\left.K^{\prime}\left(=k_{a} / k_{-a}\right)\right)$ and also the leaving ability of the thiophenolate leaving group increases (and hence $k_{\mathrm{b}}$ increases) so that the overall rate. $k_{\mathrm{N}}=K k_{\mathrm{b}}$, is strongly enhanced. Theoretical support is provided by the natural bond orbital (NBO) analy'ses at the B3LYP/6-31+G* level. The anomaly exhibited by $\mathrm{R}=\mathrm{Et}$ attests to the stepwise reaction mechanism in which the leaving group departure is rate limiting.
\end{abstract}

Keywords : Aminolysis of $S$-phenyl substituted-acetate series. Anomalous behaviors of the ethyl group, Natural bond orbital (NBO) analysis, Cross-interaction constant.

\section{Introduction}

The nucleophilic substitution reactions of S-phenyl substituted-acetate (SPA) series. $\mathrm{RC}(=\mathrm{O}) \mathrm{SAr}$ where $\mathrm{R}=\mathrm{Me}$ $\left(\mathrm{CH}_{3}\right),{ }^{l} \mathrm{Et}\left(\mathrm{CH}_{3} \mathrm{CH}_{3}\right),{ }_{i} i-\operatorname{Pr}\left(\left(\mathrm{CH}_{3}\right)_{2} \mathrm{CH}\right)^{3}{ }_{t} t-\mathrm{Bu}\left(\left(\mathrm{CH}_{3}\right)_{3} \mathrm{C}\right)^{3}$ and $\mathrm{Bn}\left(\mathrm{C}_{6} \mathrm{H}_{5} \mathrm{CH}_{2}\right){ }^{4}$ with a large excess amount of benzy lamines in acetonitrile are found to proceed by a stepwise mechanism through a tetrahedral zwitterionic intermediate, $\mathrm{T}^{ \pm}$. with rate-limiting expulsion of the leaving group. thiophenolate anion $\left(\mathrm{ArS}^{-}\right), k_{\mathrm{b}}$ in eq. 1 . Since the reactions occur in two steps, the overall rate constants, $k$; are complex. eq. 2 .

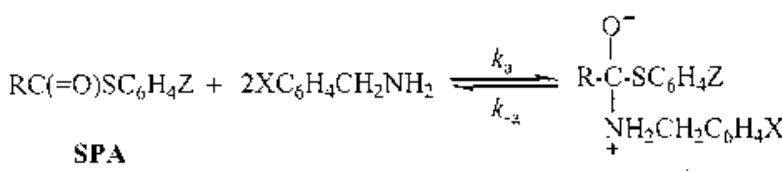

$$
\begin{aligned}
& \mathrm{T}^{ \pm} \\
& \stackrel{k_{\mathrm{b}}}{\longrightarrow} \mathrm{RC}(=\mathrm{O}) \mathrm{NHCH}_{2} \mathrm{C}_{6} \mathrm{H}_{4} \mathrm{X}+\mathrm{XC}_{6} \mathrm{H}_{4} \mathrm{CH}_{2} \stackrel{+}{+} \mathrm{H}_{3}+{ }^{-} \mathrm{SC}_{6} \mathrm{H}_{4} \mathrm{Z} \\
& k_{\mathrm{K}}=\left(k_{\mathrm{a}} / k_{-\mathrm{a}}\right) \cdot k_{\mathrm{b}}=K k_{\mathrm{b}}
\end{aligned}
$$

The reactivity and selectivity parameters including the cross-interaction constants. ${ }^{5} \rho_{\mathrm{XZ}}$. in eqs. 3 where $X$ and $Z$. represent substituents in the nucleophile and leaving group.

$$
\begin{gathered}
\log \left(k_{\mathrm{NZ}} / k_{\mathrm{HH}}\right)=\rho_{\mathrm{X}} \sigma_{\mathrm{X}}+\rho_{\mathrm{Z}} \sigma_{\mathrm{Z}}+\rho_{\mathrm{NZ}} \sigma_{\mathrm{X}} \sigma_{\mathrm{Z}} \\
\rho_{\mathrm{XZ}}=\partial \rho_{\mathrm{Z}} / \partial \sigma_{\mathrm{X}}=\partial \rho_{\mathrm{X}} / \partial \sigma_{\mathrm{Z}}
\end{gathered}
$$

respectively are summarized in Table 1 . One notes im-

${ }^{*}$ Contesponding Authors. Tel: +82-32-860-7671; Fax: $+82-32-$ 865-4855; e-mail: ilee àinha.ac.ks: hwlee ànha.ac.ks mediately from this Table anomalously high rate $\left(k_{\mathrm{N}}\right)$ and large magnitude of $\rho_{\mathrm{Xz}}$ for the $\alpha$-methyl substituted acetate, i.e., $\mathrm{R}=\mathrm{Et}$. The purpose of this work is to examine factors that are responsible for such anomalous behaviors exhibited by the $S$-phenyl acetate homologue (SPA) with $\mathrm{R}=\mathrm{Et}$. Since the Taft s polar $\left(\sigma^{*}\right)^{6}$ as well as steric effect constant $\left(E_{\mathrm{s}}\right)^{6}$ decreases. i.e., becomes more negative, by a successive $\alpha$ metlylation from $\mathrm{R}=\mathrm{Me}$ to $\mathrm{R}=t-\mathrm{Bu}$ (Table $\mathrm{l}$ ). reactivity is expected to change (increase or decrease) successively along with the increase in the number of methyl group on the $\alpha$ carbon when the same mechanism applies to all the members in the series. as normally have been observed and reported. The unexpected anomaly observed with $\mathrm{R}=\mathrm{Et}$ therefore suggests some important stereoelectronic factors operative in the transition state that are not reflected in the Taft's $\sigma^{*}$ and $E_{\mathrm{s}}$ substituent constants.

\section{Results and Discussion}

The rate constants. $k \mathrm{~N}$ in Table 1 , are correlated (excluding $\mathrm{R}=\mathrm{Et}$ ) with the Taft s polar substituent constants, $\sigma^{*}$. eq. $4^{6}$ where $k_{i}$ is the $k_{\mathrm{N}}$ value with $\mathrm{R}=\mathrm{Me}$ for which $\sigma^{*}=0$.

$$
\log \left(k_{\mathrm{N}} / k_{0}\right)=\rho^{*} \sigma^{*}
$$

Figure 1 shows that the $\rho^{*}$ value obtained for 4 R's except $\mathrm{R}=\mathrm{Et}$ is $\rho^{*}=2.97 \pm 0.22$ with correlation coefficient $\mathrm{r}=$ 0.994 . The observed reactivity of $\mathrm{R}=\mathrm{Et}$ is higher by $c a .16$ times than that derived from eq. 4 . In contrast to the good correlation of $\log k_{\text {N }} v s . \sigma^{*}$, inclusion of the steric effect (eq. $5 a)^{6}$ gave unsatisfactory correlation. eq. $5 b$, with $r=0.779$ for the $5 \mathrm{R}$ 's. 
Table 1. Reactivity paranneters for the reactions of $\mathrm{RC}(=\mathrm{O}) \mathrm{SC}_{6} \mathrm{H} \perp$ with $\mathrm{XC}_{0} \mathrm{H}_{4} \mathrm{CH}_{2} \mathrm{NH}_{2}$ in acetonitrile at $45^{\circ} \mathrm{C}$

\begin{tabular}{|c|c|c|c|c|c|c|c|c|c|c|}
\hline $\mathrm{R}$ & $\sigma^{*}$ & $E_{s}$ & $\begin{array}{l}k_{2} \times 10^{k_{2}} \\
\left(\mathrm{M}^{-1} \mathrm{~s}^{-1}\right)\end{array}$ & $\begin{array}{l}\rho_{\mathrm{X}^{b}}^{b} \\
\left(\beta_{\mathrm{X}}\right)\end{array}$ & $\begin{array}{l}\rho g^{c} \\
\left(\beta_{Z}\right)\end{array}$ & $\rho_{\times 2}$ & $\begin{array}{c}\Delta H^{-} \\
\left(\mathrm{kcal} \mathrm{mol}^{-1}\right)\end{array}$ & $\begin{array}{l}-\Delta S^{-} \\
\text {(e.u.) }\end{array}$ & $k_{\mathrm{H}} / k_{\mathrm{D}}$ & ref. \\
\hline $\mathrm{Me}, \mathrm{CH}_{3}$ & 0.00 & 0.00 & 1.65 & $\begin{array}{l}-1.40 \\
(1.36)\end{array}$ & $\begin{array}{c}5.32 \\
(-2.21)\end{array}$ & 0.90 & $5.2-6.2$ & $46-56$ & $\begin{array}{c}1.25-1.39 \\
(1.33)^{d}\end{array}$ & 1 \\
\hline Et, $\mathrm{C}_{2} \mathrm{H}_{5}$ & -0.10 & -0.07 & 13.6 & $\begin{array}{l}-2.09 \\
(2.11)\end{array}$ & $\begin{array}{c}2.74 \\
(-1.18)\end{array}$ & 2.36 & $3.9-4.6$ & $53-60$ & $\begin{array}{c}1.18-1.24 \\
(1.23)\end{array}$ & 2 \\
\hline$i-\mathrm{Pr},\left(\mathrm{CH}_{3}\right)_{2} \mathrm{CH}$ & -0.19 & -0.47 & 0.320 & $\begin{array}{l}-1.33 \\
(1.30)\end{array}$ & $\begin{array}{c}4.35 \\
(-1.82)\end{array}$ & 0.82 & $10.6-13.2$ & $30-41$ & $\begin{array}{c}1.22-1.53 \\
(1.22)\end{array}$ & 3 \\
\hline$t-\mathrm{Bu},\left(\mathrm{CH}_{3}\right)_{2} \mathrm{C}$ & -0.30 & -1.54 & $0.221^{\circ}$ & $\begin{array}{l}-1.35 \\
(1.30)\end{array}$ & $\begin{array}{c}3.65 \\
(-1.49)\end{array}$ & 1.05 & $9.9-11.5$ & $39-46$ & $\begin{array}{c}1.23-1.51 \\
(1.23)\end{array}$ & 3 \\
\hline $\mathrm{Bn}, \mathrm{C}_{\mathrm{n}} \mathrm{H}_{3} \mathrm{CH}_{2}$ & 0.22 & -0.33 & 6.68 & $\begin{array}{l}-1.50 \\
(1.55)\end{array}$ & $\begin{array}{c}1.61 \\
(-1.66)\end{array}$ & 0.92 & $4.2-5.5$ & $49-60$ & $\begin{array}{c}1.21-1.72 \\
(1.36)\end{array}$ & 4 \\
\hline
\end{tabular}

${ }^{\mathrm{x}} \mathrm{X}=p-\mathrm{MeO}$ and $\mathrm{Z}=p-\mathrm{Me}$ at $45^{\circ} \mathrm{C} .{ }^{\mathrm{h}} \mathrm{Z}=\mathrm{H} .{ }^{c} \mathrm{X}=\mathrm{H} .{ }^{d \mathrm{X}}=p-\mathrm{MeO}$ and $\mathrm{Z}=p-\mathrm{Me}$ at $45^{\circ} \mathrm{C}$. Extrapolated value from Arrhenius plot

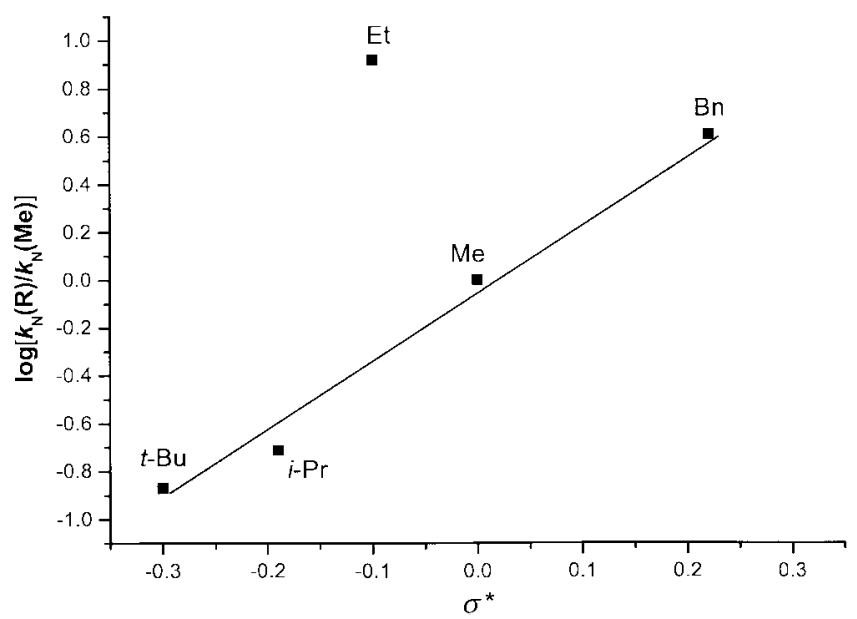

Figure 1. The plot $\log \left[k_{\mathrm{N}}(\mathrm{R}) / h_{\mathrm{r}}(\mathrm{Me})\right] \mathrm{s} s . \sigma^{-}$for the reactions of $\mathrm{RC}(=\mathrm{O}) \mathrm{SC}_{6} \mathrm{H}_{4}-p-\mathrm{CH}_{3}$ with $p-\mathrm{CH}_{3} \mathrm{OC}_{6} \mathrm{H}_{4} \mathrm{CH}_{2} \mathrm{NH}_{2}$ at $45^{\circ} \mathrm{C}$ where $\mathrm{R}=\mathrm{Me}, \mathrm{Et}, i-\mathrm{Pr}, t-\mathrm{Bu}$ and $\mathrm{Bn}$.

$$
\begin{gathered}
\log \left(k_{\mathrm{N}} / k_{i j}\right)=\rho * \sigma^{*}+S E_{\mathrm{s}} \\
\log \left(k_{\mathrm{N}} / k_{0}\right)=1.74 \pm 2.19 \sigma^{*}+0.55 \pm 0.70 E_{\mathrm{s}}
\end{gathered}
$$

For the three points $(\mathrm{R}=\mathrm{Me}, i-\mathrm{Pr}, t-\mathrm{Bu})$ correlation of $\log$ $\left(k_{\mathrm{N}} / k_{i j}\right)$ with the steric effect constants, $\left(E_{\mathrm{s}}\right)$. gave $S=0.30 \pm$ 0.05 ( $\mathrm{r}=0.987$ ); the two, $\mathrm{R}=\mathrm{Et}$ and $\mathrm{Bn}$, deviated wildly from the linearity. Comparison of the $\rho^{*}$ and $S$ values suggests that the steric effect $\left(E_{\mathrm{s}}\right)$ contributes much less (ca. one tenth) than the polar effect $\left(\sigma^{*}\right)$ to the overall rates. One reason for this could be that the steric effect is compensated by its opposite influence on the rate. In the addition step. $k_{\mathrm{a}}$. the bulkier the substituent $R$. the rate becomes more retarded by steric hindrance, whereas the rate is enlanced by steric relieving effect in the rate-limiting expulsion of the leaving group $\left(k_{\mathrm{b}}\right)$ from the intermediate, $\mathrm{T}=$. The negligible steric effect has led, of course, to the satisfactory correlation with polar effect alone (eq 4). The $\rho^{*} \sigma^{*}$ correlation (eq. 4) is expected to apply for the reaction where steric and conjugative effects do not play any role. ${ }^{67}$ For example the $S_{x} l$ and $S_{\$ 2}$ reactivities of alkyl derivatives are nomally well correlated with eq. $4^{7}$

The anonalous reactivity found with $\mathrm{R}=\mathrm{Et}$ cannot be due to the steric effect since there is no reason to believe the ethyl group has an anomalously rate enhancing streic effect. We therefore think that it is caused by a rather strong conjugative effect within the TS. Since the rate constant $k_{\mathrm{K}}$ is composed of two constants, $k_{\mathrm{N}}=K \cdot k_{\mathrm{b}}$. the rate enlancing effect can be on either $K$ or $k_{\mathrm{b}}$, or on both.

In the molecular orbital theory, the proximate (geminal and/or vicinal) bond-antibond $(\sigma-\sigma)$ charge transfer delocalization stabilizations are well established effects. ${ }^{8}$ The charge transfer takes place from a bonding orbital (which can be $\pi, \sigma$ or lone pair. $n$ ) to an unoccupied antibonding orbital (which can be $\pi^{*}$ or $\sigma^{*}$ ), represented in general as $\sigma$ $\sigma^{*}$. and the stabilization energy is given by a second-order perturbation energy. $\Delta E^{2 i} \sigma-\sigma^{*}$ in eq. 6 where $\Delta \varepsilon$ is the energy gap between the two, bonding ( $\pi, n$ or $\sigma$ type) and

$$
\Delta E^{(2)} \sigma-\sigma^{*}=-2 F^{2} \sigma \sigma^{*}\left(\varepsilon_{\sigma^{*}}-\varepsilon_{\sigma}\right) \cong-2\left(k S_{\sigma \sigma^{*}}\right)^{2} / \Delta \varepsilon
$$

antibonding, orbital levels ( $\pi^{*}$ or $\sigma^{*}$ type) and $F_{\sigma \sigma^{*}}$ is the Fock matrix element which is proportional (with a constant $k$ ) to the overlap $\left(S_{\sigma \sigma}\right)$ between the two orbitals. Now if we look at the $\mathrm{T}=$ intermediate structures, 1 and $2 \mathrm{in}$ Scheme $\mathrm{l}$, for the case of $(b)$ the $C^{2}-R^{2} \sigma$ bond is located antiperiplanar to the vicinal $\mathrm{C}^{\mathrm{l}}$-LG antibonding $\sigma^{*}$ orbital. as can be readily seen in structure 2 . The vicinal $\sigma-\sigma^{*}$ charge transfer interaction is stronger when they are antiperiplanar than they are synperiplanar to each other. ${ }^{8}$ We therefore expect that in

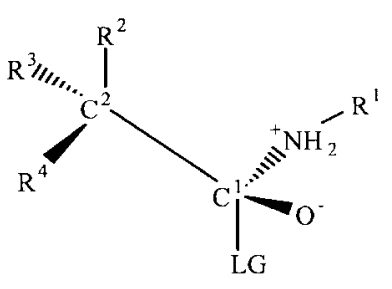

1

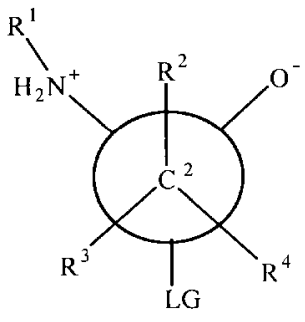

2
Scheme 1. $\mathrm{R}^{1}=\mathrm{C}_{0} \mathrm{H}_{3} \mathrm{CH}_{2}$ and $\mathrm{LG}=\mathrm{SC}_{0} \mathrm{H}_{1} \mathrm{Z}$, (a) $\mathrm{Me}: \mathrm{R}^{2}=\mathrm{R}^{3}=\mathrm{R}^{4}=\mathrm{H}$, (b) Et : $\mathrm{R}^{2}=\mathrm{CH}_{3}, \mathrm{R}^{3}=\mathrm{R}^{4}=\mathrm{H}$, (c) $i-\mathrm{Pr}: \mathrm{R}^{2}=\mathrm{R}^{3}=\mathrm{CH}_{3}, \mathrm{R}^{4}=\mathrm{H}$, (d) $t-\mathrm{Bul}$ : $\mathrm{R}^{2}=\mathrm{R}^{3}=\mathrm{R}^{4}=\mathrm{CH}_{3}$. 


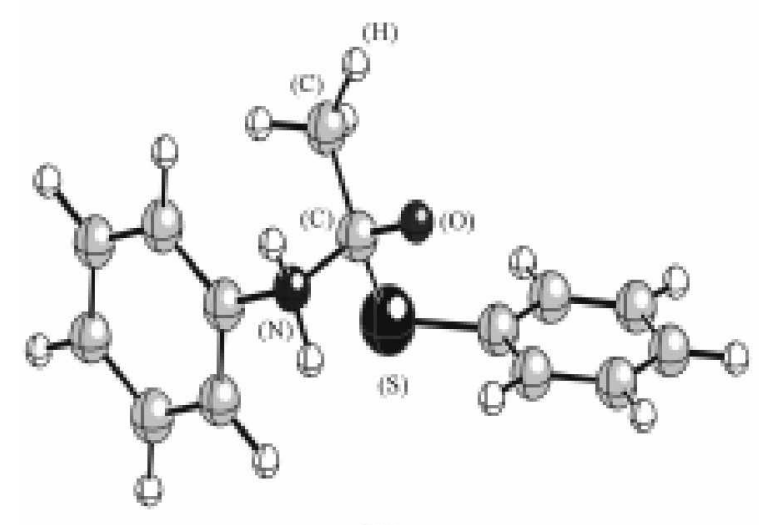

[A]

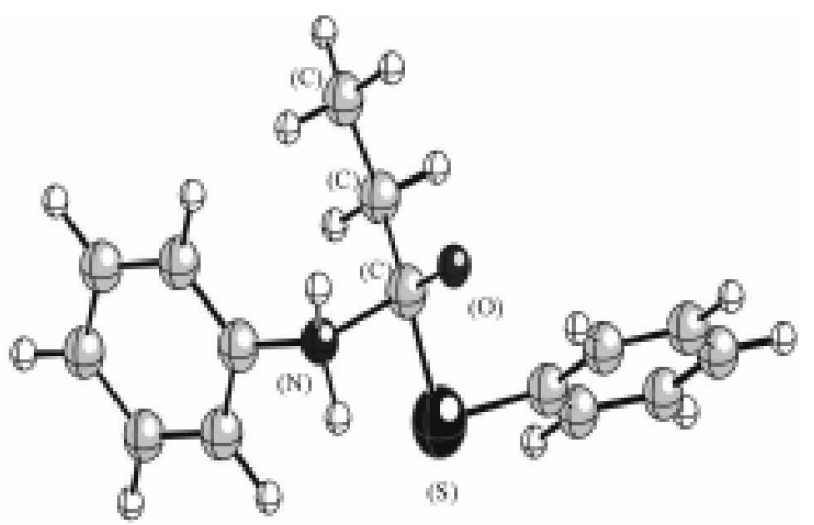

(B)

Figure 2. The structure of tetrahedral intenmediate $(\mathrm{T}=$ ) bound with aniline and $S$-phenyl methyl $(\mathrm{A})$ and ethyl $(\mathrm{B})$ acetate at the RHF/3$21 \mathrm{G}^{*} / \mathrm{RHF} / 3-2 \mathrm{lG} *$ level.

the case of (b) with $R=E t$. there will be a strong charge transfer delocalization and the structure, i.e., the $\mathrm{T}=$ intermediate, is strongly stabilized (and hence $K$ is large in eq. 2). The natural bond orbital (NBO) theory ${ }^{\mathrm{sb} \cdot \mathrm{c}}$ predicts that the $\sigma_{\mathrm{AB}}-\sigma_{\mathrm{CD}}^{*} \mathrm{NBO}$ delocalizaion leads to a decrease in A-B and C-D bond orders (and hence causes stretching of the bonds) and a sinultaneous increase in B-C bond order (causes contraction of $\mathrm{B}-\mathrm{C}$ bond). In other words the $\sigma_{\mathrm{C}, \mathrm{C}}$ $\sigma_{\text {c.s }}$ interaction in (b) leads to overall stabilization of the intermediate, $\mathrm{T}^{ \pm}$. (increase in $K$ ). but stretches the $\mathrm{C}$ - $\mathrm{S}$ bond sonewhat, which facilitates, of course. the expulsion of the leaving group, $\mathrm{ZC}_{6} \mathrm{H}_{4} \mathrm{~S}^{-}$. in the rate-liniting step (increase in $k_{\mathrm{b}}$ ). As a result, the rate is enhanced since both $K$ and $k_{\mathrm{b}}$ in eq. 2 are increased. An antiperiplanar arrangement intermediate structure is presented in Figure 2.

What about in other compounds? Since the $\sigma_{\mathrm{C}-\mathrm{H}}$ level is lower than the $\sigma_{\text {c.c }}$ level. ${ }^{\text {sa }}$ the $\sigma-\sigma^{*}$ interaction in (a) with $\mathrm{R}=\mathrm{Me}$ will be smaller due to a larger energy gap. $\Delta \varepsilon$. in eq. 6 . For $\mathrm{R}=i-\mathrm{Pr}$ (c) and $t-\mathrm{Bu}$ (d) cases, the electron-donating ability increases with an increase in the number of Me group on the $\mathrm{C}^{2}$ atom (as reflected in the alniost 2 and 3 times more negative Taft polar effect $\left(\sigma^{*}\right)$ constants $^{6}$ in Table 1$)$. As a result of this greater electron donation toward the C.S bond, the $\sigma_{c}{ }_{c}$ orbital level is raised ${ }^{9}$ and leads to a wider energy gap. $\Delta \varepsilon$, in eq. 6 and reduces the charge transfer stabilization energies, $\Delta E^{2 j} \sigma-\sigma^{*}$. Furthennore as the $\alpha$-carbon is successively methylated. steric inhibition increases in the intermediate, $T=$, which will cause stretching of the $\mathrm{C}^{\mathrm{l}}-\mathrm{C}^{\text {: }}$ bond ${ }^{8 b .3}$ and in effect the overlap. $S_{\sigma \sigma}$. decreases. These two effects, (i) wider energy gap, ( $\Delta \varepsilon=$ large), and (ii) weaker overlap. ( $S_{\sigma \sigma^{*}}=$ small) cause weak and insignificant stabilization of the $\mathrm{T}^{\mathbf{}}$ structure and the rate enhancing effect due to $\sigma_{\mathrm{C} . \mathrm{C}}-\sigma_{\mathrm{C} . \mathrm{s}}^{*}$ interaction becomes sniall (much snaller than that for $\mathrm{R}=\mathrm{Et}$ case). For $\mathrm{R}=\mathrm{Br}$, the phenyl group is a relatively strong electron-acceptor $\left(\sigma^{*}=+0.22\right)$ so that the $\sigma_{C .}$ level is depressed ${ }^{9}$ and hence $\Delta E^{(\eta)} \sigma-\sigma^{*}$, decreases due to a wider energy gap, $\Delta \varepsilon$. in eq. 6 .

We have performed natural bond orbital (NBO) analyses ${ }^{8 /-e}$ to calculate charge transfer energies using a model system (3) with $\mathrm{R}^{\mathrm{l}}=\mathrm{H}$ and $\mathrm{LG}=\mathrm{F}$ in 1 and 2 . For the ethyl case. $\mathrm{R}=\mathrm{Et}$, the $\sigma-\sigma_{\mathrm{C} . \mathrm{F}}$ vicinal charge transfer stabilization ${ }^{8}$ is the largest with $\Delta E^{2)} \sigma-\sigma^{*}=-4.9 \mathrm{kcal} \mathrm{mol}^{-1}$ at

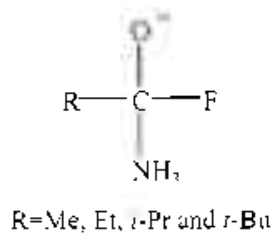

3

the B3LYP/6-3l+G* level of theory. For the $\mathrm{R}=\mathrm{Me}, i-\mathrm{Pr}$ and $t$-Bu. the corresponding stabilization energies are lower with

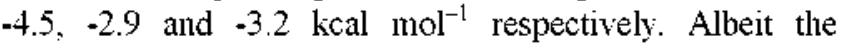
differences in the charge transfer stabilization energies are small due to the adoption of a model calculation, the expected trend is bone out in the result of our density functional theory (DFT) calculation. ${ }^{10}$

In conclusion, the vicinal $\sigma_{C . C}-\sigma_{C . S}^{*}$ charge transfer delocalization is the strongest with $\mathrm{R}=\mathrm{Et}$ due to the optimum. antiperiplanar, arrangement between $\sigma$ and $\sigma^{\prime}$ orbitals as well as the narrow energy gap. $\Delta \varepsilon$.

The most stable intermediate, $\mathrm{T}=$, with $\mathrm{R}=\mathrm{Et}$ should provide the strongest $\mathrm{C}-\mathrm{N}$ bond and hence the largest magnitude of $\rho_{\mathrm{X}}$ and $\beta_{\mathrm{X}}$ value is observed experimentally (Table 1). The strongest $\sigma-\sigma^{*}$ interaction should lead to a facile C.S bond cleavage in the rate-detemining step, $k_{b}$, and the TS is reached at an early stage with lower degree of bond cleavage. The lower degree of bond cleavage is reflected in the smaller magnitude of $\beta_{Z}$ (or $\rho_{Z}$ ) value. and also in the low activation enthalpy, $\Delta H^{*}$. in Table l. It is well known that the main component of the deformation energy.

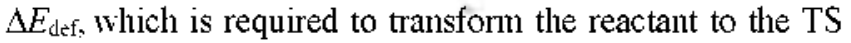
structure. is the stretching of the cleaving bond. ${ }^{\text {Il }}$ Thus a tightest TS is realized with $\mathrm{R}=\mathrm{Et}$ as evidenced by the largest positive cross-interaction constant, ${ }^{5} \rho_{x z}$. in Table 1.

The kinetic isotope effects $k_{\mathrm{H}} / k_{\mathrm{D}}$, involving deuterated benzylamine $\left(\mathrm{XC}_{6} \mathrm{H}_{4} \mathrm{CH}_{2} \mathrm{ND}_{2}\right)$ nucleophiles are all greater than unity ${ }^{12}$ and the magnitude is similar so that the $k_{\mathrm{H}} / k_{\mathrm{D}}$ values do not provide a very sensitive measure of the TS structure. 
The anomalous reactivity and large magnitude of $\rho_{\mathrm{Xz}}$ found with R=Et in the $S$-phenyl series are also found in the dithio series, $\mathrm{RC}(=\mathrm{S}) \mathrm{SC}_{6} \mathrm{H}_{4} Z$. The rate is the fastest and the $\rho_{\mathrm{X} Z}$ value is the largest with $\mathrm{R}=\mathrm{Et}$ in the dithio series studied so far $\left(\mathrm{R}=\mathrm{Me}^{13} \mathrm{Et}^{14}\right.$ and $\left.\mathrm{Bn}^{15}\right)$. If our interpretation is correct, the same anomaly will be found with $\mathrm{R}=\mathrm{Et}$ in the phenolate series, $\mathrm{RC}(=\mathrm{O}) \mathrm{OC}_{6} \mathrm{H}_{4} \mathrm{Z}$, as well as in the thiono series. $\mathrm{RC}(=\mathrm{S}) \mathrm{OC}_{6} \mathrm{H}_{4} Z$. Substitution of $\mathrm{O}$ by $\mathrm{S}$. or of $\mathrm{S}$ by $O$. does not change the strongest vicinal $\sigma_{\mathrm{CC}}-\sigma_{\mathrm{C} \text {.L }}^{*}$ charge transfer interaction expected with $\mathrm{R}=\mathrm{Et}$, as can be seen in Scheme 1. The same argument presented above for the $S$ phenyl series should apply to the other series. provided the same stepwise mechanism applies to all the members in the respective series. We stress that the anomaly observed with $\mathrm{R}=\mathrm{Et}$ is a manifestation of the stepwise mechanism through a tetrahedral zwitterionic internediate with rate-limiting expulsion of the leaving group on the grounds that : (i) If the bond formation step. in which polar effect alone is important, were rate-limiting. the rate order should have been in the order of the Taft's $\sigma^{*}$ constant; $\mathrm{R}=t-\mathrm{Bu}<i-\mathrm{Pr}<$ $\mathrm{Et}<\mathrm{Me}<\mathrm{Bn}$. (ii) If the reaction rates were affected exclusively by steric effects of the type present in reactions used to define $E_{\text {s. }}$ the rate $\left(\log k_{\mathrm{N}}\right)$ should have been well correlated with the steric effect constant, $E_{\mathrm{s}}$, alone with the susceptibility constant $S$. (iii) If the reactions proceeded by a simple concerted ( $\mathrm{S}: 2)$ process. the Taft equation (5a) should have been valid. ${ }^{7}$ (iv) If the bond cleavage were solely responsible in determining the rate. the rate order should have been in the reverse order of the Taft's $\sigma^{*}$ constants since electron donating $\mathrm{R}$ group facilitates leaving group expulsion ${ }^{16}$ : $\mathrm{R}=\mathrm{Bn}<\mathrm{Me}<\mathrm{Et}<i-\mathrm{Pr}<t$ - $\mathrm{Bu}$.

We conclude that the anomaly observed with $\mathrm{R}=\mathrm{Et}$ provides evidence for a stepwise mechanism in which the rate constant $(k \times)$ is composed of two factors as expressed by eqn. (2). Thus the observed rate is determined by both the stability $(K)$ of the intermediate, $\mathrm{T}^{ \pm}$. and nucleofugality of the leaving group $\left(k_{\mathrm{b}}\right)$. Both of these factors are outstandingly favorable for the reactions with $\mathrm{R}=\mathrm{Et}$ due to the strong vicinal $\sigma_{\mathrm{C}-}$ $\sigma_{c s s}^{*}$ charge transfer interaction in the intermediate, $\mathrm{T}^{ \pm}$. Further experimental as well as theoretical works are in progress to support our arguments presented in this work.

Calculations. Ab initio MO calculations were performed with Gaussian 98 system of progranss. ${ }^{17}$ Geometries were optimized at the B3LYP/6-3I+G* level of theory. The natural bond orbital $(\mathrm{NBO})$ analyses were carried out to obtain proximate bond - antibond $\left(\sigma-\sigma^{*}\right)$ orbital interaction energies $\left(\Delta E^{2)} \sigma-\sigma^{*}\right)$ at the NBO-B3LYP/6-31+ $\mathrm{G}^{*}$ level.

Acknowledgment. This paper is dedicated to Prof. Kyung-Hoon Jung on the occasion of his 65th anniversary. This work was supported by grant No. R-01-1999-00047 from the Basic Research Program of the Korea Science and Engineering Foundation. We also thank Inha University for support of this work.

\section{References}

1. Oh. H. K.: Yang, J. H.: Lee, H. W.; Lee. I. Bull Korean Chem. Soc. 1999. 20. 1418.

2. Oh. H. K.: Yang. T. H.: Cho. I. H.: Lee. H. W.: Lee. I. Int. J. Chent Kinet. 2001. 32.485.

3. Oh. H. K.: Park. C. Y.: Lee. J. M.: Lee. I. Bull. Kowan Chem. Soc 2001. 22, 383 .

4. Oh. H. K; Kim, S. K; Lee, I. Bull. Korean Chem. Soc. 1999. 20. 1017.

5. (a) Lee. I. Chem Soc. Rev 1990. 19. 317. (b) Lee. I. Adh: Phws Org. Chent 1992. 27. 57. (c) Lee. I.: Lee. H. W. Coll Czech. Chem. Conmun. 1999, 64, 1529 .

6. Taft, R. W. Jr. In Steric Effects in Organic Chemistry, Newman. M. S., Ed.: Wiley: New York, 1956; ch. 13.

7. Klumpp. G. W. Reactinity in Organic Chemismy: Wiley: New York. 1982: ch. 3.

8. (a) Epiotis. N. D.: Cherry. W. R.: Shaik. S. S.: Yates. R. L: Bernardi, F. Structural Theony of Organic Chemistry: SpringerVerlag: Berlin. 1977; part I and IV. (b) Reed. A. E.; Curtiss. L. A.: Weinhold, F. Chem. Rev 1988. 88, 899. (c) Glendening, E. D. Weinhold. F. J. Contput Chent 1998. 19.593. (d) Glendening. E. D.: Weinhold. F. J. Conput. Chem. 1998. 19.610. (e) Glendening. E. D.: Badenhoop. T. K.: Weinhold. F. J. Conput. Chem 1998. 19. 628. (f) Musso, G. F.: Figari, G.; Magnasco, V. J. Chem. Soc. Faraday Trans. 2 1985, 81, 1243. (g) Carballeira, L.: Perez-Juste. I. J. Phis. Chem A 2000. 104.9362.

9. Fleming. I. Frontier Orbitals and Organic Chentical Reactions: Wiley: London. 1976: ch. 4.

10. (a) Becke. A. D. J Chent. Phys. 1993. 98.5648 (b) Lee. C.: Yong. W. Parr. R. G. Phys. Rev $B$ 1988, 37.785. (c) Foresman, J. B. Frisch. E. Exploring Chemistry with Electronic Stuctur Theory, Gaussian Inc: Pittsburgh. 1993.

11. (a) Shaik. S. S.: Schlegel. H. B.: Wolte. S. Theoretical Aspects of Phusical Organic Chemism: The S, Mechanism: Wiley: New York. 1992: ch. 4. (b) Mitchell. D. J.: Schlegel. H. B.: Shaik. S. S.: Wolte, S. Can. J. Chem. 1985. 63. 1642.

12. Lee. I. Chem Soc. Rev. 1995, 24. 223.

13. Oh. H. K.; Woo. S. Y.: Shin, C. H.: Park, Y. S.; Lee. I. J. Org. Chent 1997. 62.5780.

14. Oh. H. K.: Kim. S. K.: Lee. H. W.: Lee. I. New J. Chen. 2001.25. 313.

15. Oh. H. K.; Kim. S. K: Cho, I. H.: Lee. H. W.; Lee, I. J. Chem. Soc. Perkin Trans. 22000.2306.

16. (a) Lee. I; Lee. D.: Kim. C. K. J. Phys. Chem A 1997, 101. 879. (b) Lee. I.: Kim. C. K.: Li. H. K.: Solnn. C. K.: Kim. C. K.: Lee. H. W. Lee. B.-S. J. An Chem. Soc. 2000. 122.11162.

17. Frisch. M. J.: Trucks. G. W.: Schlegel. H. B.: Scuseria. G. E.: Robb, M. A.; Cheeseman. J. R.: Zakrzewski, V. G.: Montgomery, J. A.. Jr.; Stratmann, R. E.; Burant, J. C.: Dapprich, S.; Millam. J. M.: Daniels. A. D.; Kudin. K. N.: Strain. M. C.: Farkas. O.; Tomasi. .T: Barone. V.: Cossi. M.: Cammi. R.: Mennucei. B.: Pomelli. C.: Adamo. C.: Clifford. S.: Ochterski. T.: Petersson. G. A.: Ayala. P. Y.: Cui. Q.: Morokuma. K.: Malick. D. K.: Rabuck. A. D.; Raghavachari, K.; Foresman. J. B; Cioslowski. J: Ortiz, J. V: Stefanov. B. B.: Liu. G.: Liashenko. A.: Piskorz. P.: Komaromi. I.: Gomperts, R.: Martin, R. L.; Fox. D. J.; Keith. T: Al-Laham. M. A.: Peng. C. Y: Nanayakkara. A.: Gonzalez. C.: Challacombe M.: Gill. P. M. W.: John1sont. B.: Chent. W.: Wong. M. W.: Andres. J. L.: Gonzalez. C.: Head Gordon. M.: Replogle. E. S.; Pople. J. A. Gaussian 98. Revision A.6: Gaussian, Inc. Pittsburgh PA. 1998. 